Uluslararası Mühendislik

Cilt/Volume:12 Sayı/Issue:1 Ocak/January 2020

Araştırma Makalesi / Research Article

\title{
Estimation of Pipeline Embedment in Soft Submarine Soils by Different Methods
}

\author{
Zeynep H. Özkul ${ }^{1}$ \\ ${ }^{1}$ Ankara Yıldırım Beyazıt Universitesi, Faculty of Engineering and Natural Sciences, Department of Civil Engineering, Ankara
}

\begin{abstract}
The embedment of subsea pipelines in soft submarine clay is a key parameter in pipe-soil interaction studies of offshore deep water oil and gas field developments. A number of calculation methodologies exist, some of which are based on empirical evidence. Pipeline embedment depends on the active undrained shear strength and unit weight of the soil and the properties of the pipeline (i.e. weight and dimensions). The embedment is also influenced by stress concentrations occuring due to the geometry of the pipe catenary and by the cyclic motion of the catenary at the touchdown point. In this study, the methods typically used in the industry, such as those proposed by Terzaghi (1967), Dunlap et al. (1990) and Verley \& Lund (1995) are compared with the methods recommended in DNVGL-RP-F114 (2017). The calculated embedment from each method are compared for typical pipe properties and soil strength and discussed in view of field observations reported in the literature. The older methods were found to typically underestimate embedment for low shear strength profiles.
\end{abstract}

\section{Key Words}

"pipeline embedment", "bearing capacity", "marine clays", "pipe soil interaction" 


\section{Introduction}

The life-long integrity of pipelines in offshore deep water oil and gas projects is critical for the safe and profitable operation of a site. The embedment of these exposed pipelines is a significant factor influencing its on-bottom stability and buckling potential. At many locations, these pipelines rest on, and are partially embedded in very soft clay-rich marine sediments. They are exposed to a variety of environmental loading conditions including waves and bottom currents.

Accurate prediction of on-bottom pipeline embedment has been a subject of study for a number of decades. Offshore pipelines are subjected to oscillatory forces and displacements during installation and to wave and/or current loads during operation (Wolfram et al., 1987; Allen et al., 1989; Hale et al., 1989 and AGA/PRC, 1993). Pipeline embedment essentially determines the magnitude of the pipe-soil contact area which, in turn, affects the soil resistance that may be mobilized during axial and lateral movements of the pipeline. Hence, the degree of embedment impacts both the on-bottom stability and the internal stresses that develop within the pipe cross-section.

In the late 1980's, the PIPESTAB project conducted by SINTEF (Wagner et al. 1987) and those by the American Gas Association/ Pipeline Research Committee (AGA/PRC, 1993) developed models for use in clays. Models based on empirical evidence were proposed by Dunlap et al. (1990) and Verley and Lund (1995). Upper and lower bound plasticity solutions to the embedment problem in clay were presented by Murff et al. (1989). White and colleagues published numerous papers on the topic as part of the SAFEBUCK JIP (Randolph and White, 2008; Westgate et al, 2010; White et al., 2015; White et al, 2017). Based on improved understanding of the mechanisms involved, revised guidelines were published in DNVGL-RP-F114 (2017) for the calculation of pipeline embedment under drained and undrained loading conditions.

Many projects designed and constructed prior to the latest publications have used earlier empirically derived methods. It will be useful to operators of such assets to evaluate how the results of these earlier methods compare with those that are currently recommended. In this study, pipeline embedment calculations based on the frequently used Dunlap et al. (1990) and Verley and Lund (1995) methods are compared with the more recently recommended DNVGL-RP-F114 (2017) method. Parameters used in the calculations include two pipeline sizes and three soil profiles typical of the highly plastic clays found in the deep water subsea environment.

\section{Materials and Methods}

\subsection{Design Parameters}

The pipeline properties used in this study are summarized in Table 1. Offshore pipelines are designed and manufactured specific to each site. Pipe 1 and Pipe 2 are examples of production and gas export pipelines used in the industry. Their specific gravity is 1.44 for Pipe 1 and 1.79 for Pipe 2. The soil properties used in this study are summarized in Table 2. They are based on unit weight and minivane tests conducted on box core samples collected from the top $1 \mathrm{~m}$ of the seabed. Undisturbed and remolded design soil strength parameters shown are valid for the top $0.6 \mathrm{~m}$ of the seabed (i.e. maximum depth of testing). A range of shear strengths are generally encountered along a pipeline route. This variability is accounted for by using multiple representative profiles: high, average and low strength profiles.

Table 1. Pipeline Parameters

\begin{tabular}{llll}
\hline Pipe Property & Units & Pipe 1 & Pipe 2 \\
\hline Steel density & $\mathrm{kg} / \mathrm{m}^{3}$ & 7846 & 7846 \\
Seawater density & $\mathrm{kg} / \mathrm{m}^{3}$ & 1025 & 1025 \\
Outer diameter (coated), D & $\mathrm{m}$ & 0.413 & 0.330 \\
Unit weight (empty) in air & $\mathrm{N} / \mathrm{m}$ & $1,933.7$ & 1539.7 \\
Unit weight (empty) submerged, P & $\mathrm{N} / \mathrm{m}$ & 588.1 & 680.1 \\
Pipe Bearing Pressure, P/D & $\mathrm{N} / \mathrm{m}^{2}$ & 1,424 & 2,061
\end{tabular}

Table 2. Soil Parameters

\begin{tabular}{lllll}
\hline Soil Property & Units & \multicolumn{2}{l}{ Soil Parameter Range } & High \\
\hline Undrained shear strength at mudline & & Low & Average & 1.293 \\
Undrained shear strength at 0.61 m & $\mathrm{kN} / \mathrm{m}^{2}$ & 0.479 & 0.958 & 10.204 \\
Remolded shear strength at mudline & $\mathrm{kN} / \mathrm{m}^{2}$ & 6.708 & 8.624 & 0.431 \\
Remolded shear strength at 0.61 m & $\mathrm{kN} / \mathrm{m}^{2}$ & 0.096 & 0.287 & 3.593 \\
Submerged unit weight of soil at mudline & $\mathrm{kN} / \mathrm{m}^{2}$ & 1.533 & 2.300 & 3.14 \\
Submerged unit weight of soil at $0.61 \mathrm{~m}$ & $\mathrm{kN} / \mathrm{m}^{3}$ & 2.51 & 2.83 & 4.87 \\
\hline
\end{tabular}




\subsection{Design Approach}

Figure 1 shows a cross-section of a pipeline with outer diameter, $\mathrm{D}_{\mathrm{o}}$, and submerged empty weight, $\mathrm{P}$, embedded to a depth $\mathrm{z}$, on the seabed. The embedded portion of the pipe forms a segment of the pipe cross-sectional area. A line passing through the corner of this segment at mudline and the center of the pipe forms an angle $\theta$ with the vertical. Because of the circular shape, both $\theta$ and the width of the bearing area, B, are functions of embedment $\mathrm{z}$.

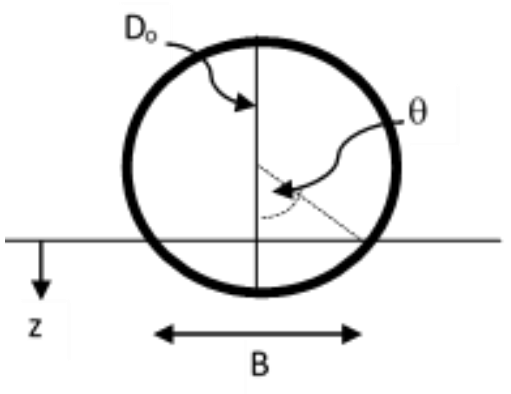

Figure 1. Partially embedded pipeline resting on the seabed.

The undrained vertical embedment problem shown in this figure may be solved using a number of different calculation models as described below. The embedment value calculated using classical bearing capacity analysis is sometimes referred to as the "static embedment" since it considers only the influence of the pipeline's static submerged weight, $\mathrm{P}$, and neglects any other effects caused by the installation process. The pipe laying process produces both stress concentrations at the touch-down point (due to the pipeline catenary) as well as dynamic effects caused by the horizontal and vertical motions of the pipeline. The as-laid embedment, obtained from field survey studies, has been found to be significantly larger (Westgate et al., 2010) than this static embedment. To account for these effects, empirical equations based on observed field and laboratory findings were developed and used in the industry. Such methods include those proposed by Dunlap et al. (1990) and by Verley and Lund (1995).

It is important to note that the soil's resistance to penetration depends on the undrained shear strength that is active at the time of penetration. The pipe-laying process inevitably causes cyclic vertical and horizontal motions at the touch down point which result in partial to full remolding of the soil. There are also stress concentrations at the touch down point due to the shape of the pipeline catenary. The influence of these effects is to increase the amount of embedment to values that are higher than would be expected based solely on the static self-weight of the pipeline and the undisturbed strength of the soil.

In order to obtain realistic embedment values, calculations may be made using one of two accepted modifications: (i) use of undisturbed undrained soil shear strengths combined with an appropriate dynamic embedment factor applied to the submerged pipe weight (Bruton et al., 2009) or (ii) use of the remolded undrained shear strength without increasing the weight of the pipe. In this study, the first approach is used for the Terzaghi, Dunlap et al. (1990) and Verley and Lund (1995) methods with a dynamic embedment factor of 2 . This is because these methods are essentially empirical in nature and have been calibrated to undisturbed shear strengths. The second approach, which is recommended in DNV, is used for the DNV method.

Westgate et al. (2010) compared field survey measurements taken at $1 \mathrm{~m}$ intervals along a $13 \mathrm{~km}$ long pipeline with embedment values calculated using (a) intact $s_{u}$ combined with the static overstress pipe weight (b) remolded $s_{u}$ combined with the static overstress weight and (c) remolded $s_{u}$ combined with a dynamic analysis of the stress concentration using Orcaflex. The field measured embedment ratios (i.e. z/D) showed a distribution ranging from values as small as 0.05 to those as high as 0.55 . They found that the embedment calculated using the fully remolded strength coupled with the static overstress matched the most frequently observed embedment well. They suggest that this calculation approach leads to reasonable estimates of the average embedment for the average lay condition.

\subsubsection{Classical bearing capacity}

At the simplest level, Terzaghi's bearing capacity theory may be used. The embedment in this case is the depth where the required bearing width (based on the submerged weight of the pipe and the seabed soil strength) and the pipe bearing area, B are equal. This is expressed by equation (1). Typically, the undrained strength of marine clays are modelled using a linear strength profile with a small positive strength, $s_{u 0}$, at mudline and a linear strength increment ratio $\Delta s_{u}$ per unit depth. The entire pipe-soil system is submerged in seawater, hence, the correct weights to use for the soil and the pipeline are their respective submerged weights $\left(\gamma^{\prime}\right.$ for soil and $P$ per unit length of pipeline).

$$
2 \sqrt{z\left(D_{o}-z\right)}=\frac{P}{\left(s_{u 0}+z \Delta s_{u}\right) N_{c}+\left(\gamma^{\prime} z\right)}
$$

It is important to note that a modification to the bearing capacity factor, $N_{c}$, is necessary when applying the bearing capacity equation shown in equation (1). Because of the round base, the ultimate bearing capacity factor is smaller for pipelines than it is for a (flat base) strip footing. Zhao et al. (2009) presented slip-line field solutions for the ultimate load capacity of submarine pipelines and found that the $N_{c}$ value decreased from 5.14 at zero embedment to a minimum value of 4 at an embedment of half the diameter in 
the case of a smooth pipe-soil contact surface. In order not to introduce additional complexity into equation (1) and still remain on the conservative side, a reduced value of $N_{c}$ is used (i.e. $2 / 3$ of 5.14) in this study.

\subsubsection{Method proposed by Dunlap et al (1990)}

Dunlap et al. (1990) conducted a series of monotonic load tests and established the following relationship for predicting pipeline embedment.

$$
H=\frac{0.01573}{D^{0.7822}}\left(\frac{F}{C_{u}\left(\frac{v}{D}\right)^{n}}\right)^{1.7822}
$$

Here $F$ is the applied force, $D$ is the pipe diameter, $c_{u}$ is the sediment undrained shear strength, $H$ is pipeline embedment and $v$ is the velocity of pipe penetration and $n$ is the visco-elastic rate constant of the sediment (taken as 0.3 for the tested soil).

\subsubsection{Method proposed by Verley and Lund (1995)}

The pipe soil model proposed by Verley and Lund (1995) for predicting the initial penetration of a pipeline uses the nondimensional parameters $S$ and $G$ calculated using the pipe outer diameter, $D$, the undrained shear strength of soil, $s_{u}$, and the soil submerged unit weight, $\gamma_{s}$. and the contact force, $F_{c}$ between the pipe and soil. The expression is shown below.

$$
\left(\frac{z}{D}\right)_{\text {init }}=0.0071\left(S G^{0.3}\right)^{3.2}+0.062\left(S G^{0.3}\right)^{0.7}
$$

Where

$$
S=\frac{F_{c}}{D s_{u}} \quad G=\frac{s_{u}}{D \gamma_{s}} \quad F_{c}=P-F_{l}
$$

The contact force, $F_{c}$, may differ from the submerged weight of the pipe if the pipe is subjected to lift forces, $F_{l}$, or stress concentrations at the point of contact. The above expression is based on an empirical fit to large and small labortory data obtained from a number of resources. Hence, it is valid for the following range of parameters: clays with $s_{u}$ ranging from 0.8 to $70 \mathrm{kPa}$, pipe diameters ranging from 0.2 to $1 \mathrm{~m}$, and specific weight of pipe ranging from 1.06 to 2.5 . These intervals correspond to $S$ and $G$ values ranging from 0.05 to 7.5 and 0.02 to 5.0 respectively. The sensitivity of $G$ to the soil unit weight, $\gamma_{s}$, is low and a value of $18 \mathrm{kN} / \mathrm{m}^{3}$ may be used for all soils. It is noted that the database used in determining the expression for initial penetration is limited to maximum pipe penetrations, $z / D$, of 0.35 .

\subsubsection{Method in DNV Recommended Guidelines}

For a pipe pushed vertically into the soil, the embedment depth is the depth were the pipe contact force is in equilibrium with the bearing capacity of the seabed soil. DNV recommended practice DNVGL-RP-F114 (2017) describes two models for the calculation of this embedment which occurs under undrained loading conditions. Both are stated to give comparable results. In Model 2, the vertical penetration resistance (including depth effects), $Q_{v}$, is calculated as shown by equation (4).

$$
Q_{v}=\left\{\min \left[6\left(\frac{z}{D}\right)^{0.25} ; 3.4\left(\frac{10 z}{D}\right)^{0.5}\right]+1.5 \frac{\gamma^{\prime} A_{b m}}{D s_{u}}\right\} D s_{u}
$$

Here $s_{u}$ is the soil undrained shear strength at the pipe invert (and therefore is a function of $\mathrm{z}$ ); $D$ is the pipe outside diameter including coating; $z$ is the pipe embedment; $\gamma^{\prime}$ is the soil submerged unit weight and $A_{b m}$ is the area of the pipe segment which lies below mudline and is a function of $z$ as shown by equation (5).

$$
\begin{array}{ll}
A_{b m}=\arcsin (B / D) \frac{D^{2}}{4}-\frac{B D}{4} \cos (\arcsin (B / D) & \text { for } z<D / 2 \\
A_{b m}=\pi D^{2} / 8+D(z-D / 2) & \text { for } z \geq D / 2
\end{array}
$$

The DNV method is not empirically derived. It accounts for a number of physical phenomenon observed around pipelines. The first term represents the soil resistance to pipe penetration. As the pipeline embeds, the buoyancy of the soft clay reduces the weight of the pipe with higher reductions at higher embedment values. The second term in equation (4) accounts for this reduction in vertical load by adding the term $\gamma^{\prime} A_{b m}$ to the soil resistance. As the seabed clay is displaced, a certain amount of soil heave occurs 
along the outer edge of the pipeline, adding to the nominal embedment. The effect of this heave is to increase the buoyancy of the pipe by about 50\% (based on best-fit numerical analysis) (Merifield et al., 2008). Model 2 accounts for the effect of heave by applying heave factor of 1.5 to the term $\gamma^{\prime} A_{b m}$ in equation (4). It is noted that at very high embedment ratios (z/D $\left.>0.5\right)$ equation (4) may underestimate the penetration resistance. In those cases, alternative bearing capacity factors may be found in Martin and White (2012).

\section{Results}

The embedment results from the four methods used are summarized in Table 3. The Terzaghi bearing capacity solution gives the smallest embedment value for all cases. Although, the pipe weight was increased, this method inherently does not account for dynamic effects in any manner. The Dunlup et al (1990) and Verley and Lund (1995) methods which are empirical in nature and which have been calibrated by lab and field observations, result in higher, more reasonable embedment values. Both of these methods give reasonably close estimates. The DNV method gives embedments lower than the empirical methods for the higher shear strength profile, similar values for the average strength profile and the highest values for the lower strength profile.

Table 3. Pipeline Embedment Results

\begin{tabular}{|c|c|c|c|c|c|c|c|c|}
\hline \multirow{2}{*}{$\begin{array}{l}\text { Pipe } \\
\text { ID }\end{array}$} & \multirow{2}{*}{$\begin{array}{l}\text { Subm. } \\
\text { Pipe } \\
\text { Weight, P } \\
\text { (N/m) }\end{array}$} & \multirow{2}{*}{$\begin{array}{l}\text { Outer } \\
\text { Diam., } \\
\text { D (m) }\end{array}$} & \multirow{2}{*}{$\begin{array}{l}\text { Soil } \\
\text { Strength } \\
\text { Profile }\end{array}$} & \multirow{2}{*}{$\begin{array}{l}\text { Norm. } \\
\text { Vert. } \\
\text { Load }\end{array}$} & \multicolumn{4}{|c|}{ Embedment, cm - \% D } \\
\hline & & & & & Terzaghi & $\begin{array}{l}\text { Dunlap et. } \\
\text { al (1990) }\end{array}$ & $\begin{array}{l}\text { Verley \& } \\
\text { Lund (1995) }\end{array}$ & $\begin{array}{l}\text { DNVGL- } \\
\text { RP-F114 } \\
(2017)\end{array}$ \\
\hline \multirow[t]{3}{*}{1} & 588 & 0.413 & High & 0.194 & $2.63-6.4$ & $5.32-12.9$ & $4.94-12.0$ & $3.17-7.7$ \\
\hline & & & Average & 0.232 & $3.71-9.0$ & $6.72-16.3$ & $6.08-14.7$ & $5.05-12.2$ \\
\hline & & & Low & 0.303 & $6.23-15.1$ & $9.31-22.6$ & $8.61-20.9$ & $9.53-23.1$ \\
\hline \multirow[t]{3}{*}{2} & 680 & 0.330 & High & 0.337 & $3.81-11.6$ & $6.55-19.9$ & $6.90-20.9$ & $5.02-15.2$ \\
\hline & & & Average & 0.404 & $5.19-15.7$ & $8.06-24.4$ & $8.64-26.2$ & $7.94-24.1$ \\
\hline & & & Low & 0.535 & $8.30-25.2$ & $11.32-34.3$ & $12.15-36.8$ & $13.17-39.9$ \\
\hline
\end{tabular}

Use of remolded shear strength in the three older methods are not appropriate since they are empirical in nature and have been calibrated to observed embedment using intact strength. The DNV method which takes into consideration the influence of numerous mechanisms and which is essentially deterministic in nature, is able to better accommodate for remolding of the soil.

The DNV method produces a wider range of embedment ratios for the three soil profiles used. For Pipe 1 the embedment ranges from $7.7 \%$ to $23.1 \%$ depending on the soil strength. This more closely resembles the wide spread of embedment observed in the field.

In order to compare embedment results for different pipe sizes and soil strengths the static bearing pressure (weight of pipe divided by its diameter) and the normalized vertical load may be used. The pipe bearing pressures are shown in Table 1 . The normalized vertical load is the submerged empty weight of the pipeline divided by its diameter and the shear strength of the soil at a depth of one diameter, $\mathrm{s}_{\mathrm{u} 1 \mathrm{D}}$. It is a dimensionless parameter and the calculated values are shown in Table 3 for each of the cases considered. Figure 1 shows embedment with respect to the pipe bearing pressure. In this figure results are plotted using solid lines for data obtained using the high strength profile, large dashed lines for those obtained using the average strength profile and small dashed lines for those obtained using the low strength profile. It can be seen that the chosen strength profile has a very significant impact on the range of embedment values obtained. As expected higher strengths result in lower embedment. The influence of the analysis method chosen can also be observed: (1) the static embedment (as calculated using classical bearing capacity analysis) consistently gives the lowest embedment and (2) the deterministic based DNVGL method produces increasingly higher embedment (as compared to the empirical based methods) as the bearing pressure increases and the soil strength decreases.

Figure 2 shows embedment versus the normalized vertical load. Use of the normalized vertical load allows for convenience in comparing different combinations (or categories) of soil strength and pipe weight. It is noted however that it does not necessarily reflect the vertical loads used in the calculations since (i) in the empirical methods a dynamic embedment factor of 2 is applied and (ii) in the DNVGL method the remolded shear strengths are used instead of the undisturbed values. 


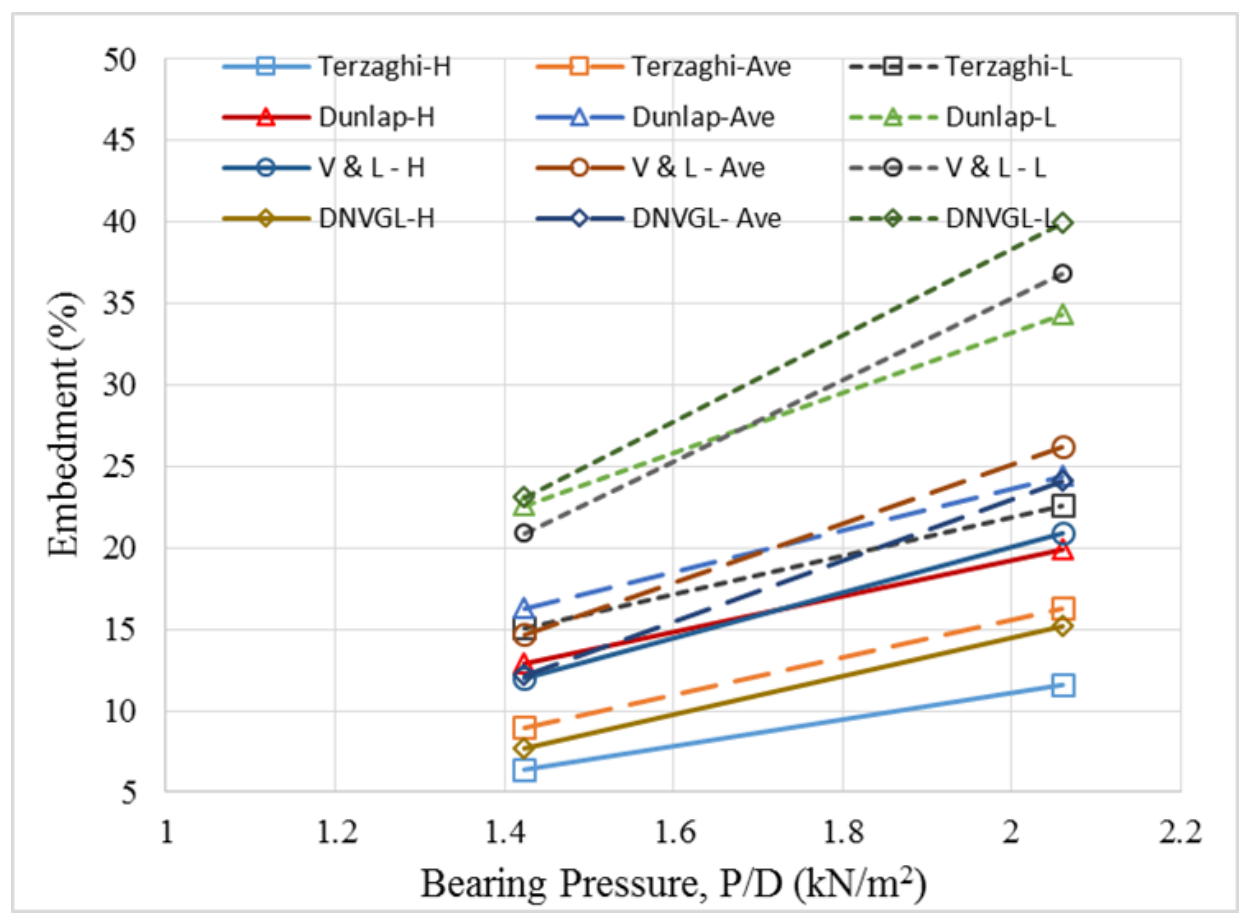

Figure. 1. Embedment versus Bearing Pressure

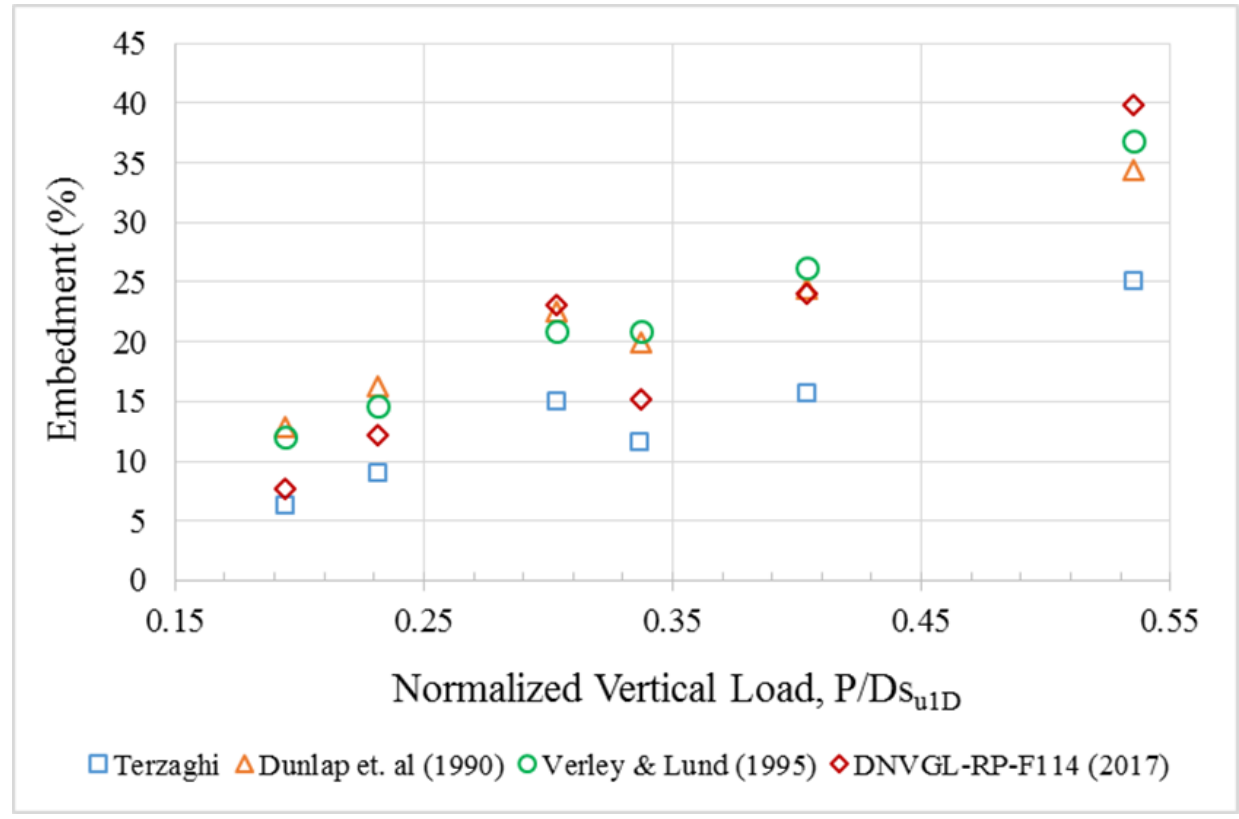

Figure. 2. Embedment versus Normalized Vertical Load

\section{Conclusions}

Calculation of pipeline embedment using classical bearing capacity equations result in embedment values that are significantly lower than those observed in the field. Hence, other models to estimate embedment have been developed over the years. In this study pipeline embedment values were calculated using four different methods commonly used in the oil and gas industry. Two representative pipe cross-sections and three soil strength profiles were used for this comparison. The empirically derived equations and the method recommended by DNV gave similar embedment values for the average shear strength profile. The DNV method gives lower embedment values for higher shear strength profiles and higher embedment values for lower strength profiles. The DNV method also produces a larger range of embedment values for a given set of soil strength profiles. 


\section{References}

AGA/PRC. (1993). Submarine Pipeline On-Bottom Stability Vol 1 Analysis and Design Guidelines. Report PR-178-9333: American Gas Association.

Allen, D.W., Lammert, W.F. \& Hale, J.R. (1989). Submarine Pipeline On-Bottom Stability: Recent AGA Research, OTC\#6055. Proc. of the 21st Offshore Technology Conf. Houston, Texas: SPE.

Bruton, D. A. S., White, D. J., Langford, T. and Hill, A. J. (2009). Techniques for assessment of pipe/soil interaction forces for future deepwater developments. OTC\#20096. Proc. of the Offshore Technology Conf. Houston, Texas: SPE.

Det Norske Veritas. (2017). Recommended Practice, Pipe-soil Interaction for Submarine Pipelines. DNVGL-RP-F114: Norway.

Dunlap, W.A., Bhojanala, R.P. \& Morris, D.V. (1990). Burial of Vertically Loaded Offshore Pipelines in Weak Sediments. OTC\#6375. Proc. of the 22nd Offshore Technology Conf. May 7-10. Houston, Texas: SPE.

Hale, J.R., Lammert, W.F. \& Jacobsen, V. (1989). Improved Basis for Static Stability Analysis and Design of Marine Pipelines. OTC \#6059. Proc. of the $21^{\text {st }}$ Offshore Technology Conf. Houston, Texas: SPE.

Martin, C. M. \& White, D. J. (2012). Limit analysis of the undrained bearing capacity of offshore pipelines. Geotechnique, 62(9), 847-863. dx.doi.org/10.1680/geot.12.OG.016

Murff, J.D., Wagner, D.A., \& Randolph, M.F. (1989). Pipe Penetration in Cohesive Soil. Geotechnique, 39(2), $213-229$.

Randolph, M. F. \& White, D. J. (2008). Pipeline Embedment in Deep Water: Processes and Quantitative Assessment. OTC \#19128. Proc. of the Offshore Technology Conf., 5-8 May, Houston, Texas: SPE.

Terzaghi, K. (1943). Theoretical Soil Mechanics. New York: John Wiley \& Sons, Inc.

Verley, R. \& Lund, K. M. (1995). A Soil Resistance Model for Pipelines Placed on Clay Soils. ASME. J. Offshore Mechanics and Arctic Engineering, Vol. V, 225-232.

Wagner, D.A., Murff, J.D., Brennodden, H. \& Sveggen, O. (1987). Pipe-Soil Interaction Model. OTC\#5504. Proc. of the 19th Offshore Technology Conf. Houston, Texas: SPE.

Westgate, Z.J., White, D.J., Randolph, M. F. and Brunning, P. (2010). Pipeline Laying and Embedment in Soft Fine-Grained Soils: Field Observations and Numerical Simulations. OTC\#20407. Proc. of the Offshore Technology Conf., Houston, Texas: SPE.

White, D. J., Westgate, Z. J., Ballard, J-C., de Brier, C. and Bransby, M. F. (2015). Best Practice Geotechnical Characterization and Pipe-Soil Interaction Analysis for HPHT Pipeline Design. OTC\#26026-MS. Proc. of the Offshore Technology Conf., 4-7 May, Houston, Texas: SPE.

White, D. J., Clukey, E. C., Boylan, N. P, Bransby, M. F., Zakeri, A., Hill, A. J. and Jaeck, C. (2017). The State of Knowledge of Pipe-Soil Interaction for On-Bottom Pipeline Design. OTC-27623-MS. Proc. of the Offshore Technology Conf. 1-4 May. Houston, Texas: SPE.

Wolfram, W.R., Getz, J.R. \& Verley, R.L.P. (1987). PIPESTAB Project: Improved Design Basis for Submarine Pipeline Stability. OTC\#5501. Proc. of the 19th Offshore Technology Conf. Houston, Texas: SPE.

Zhao, B., Gao, F., Liu, J. \& Wu, Y. (2009). Vertical Bearing Capacity of a Partially-Embedded Pipeline on Tresca Soils. Proc. International Offshore and Polar Engineering Conf. June 21-26. Osaka, Japan, 469-473. 